\title{
Self-Evaluated Negative Classroom Behavior and Speaking Performance
}

\author{
Hendi Pratama ${ }^{1} \&$ Dara Ningmara Sagita ${ }^{1}$ \\ ${ }^{1}$ Faculty of Language and Arts, Semarang State University, Semarang Indonesia \\ Correspondence: Hendi Pratama, Faculty of Language and Arts, Semarang State University, Semarang Indonesia.
}

Received: January 9, 2015

Accepted: January 23, 2015

Available online: February 11, 2015

doi:10.11114/ijsss.v3i2.674

URL: http://dx.doi.org/10.11114/ijsss.v3i2.674

\begin{abstract}
This study attempts to provide empirical data to support the claim that negative behaviors of the students can hamper their academic achievement. A particular skill in second language is opted to represent the dependent variable. Forty junior high school students join a speaking test and scored by three raters. They are also asked to rate themselves whether they have one or more negative behaviors adapted from Woodcock Johnson III test. The results show that there is a weak correlation between negative classroom behavior and speaking performance.
\end{abstract}

Keywords: negative behaviors, speaking performance.

\section{Background}

The relationship between classroom behavior and academic achievement seems to be self-explanatory. Well-maintained and controlled classroom behavior leads to successful academic results. On the other hand, disruptive and uncontrolled behavior leads to poor academic achievement. This study attempts to support the seemingly self-explanatory relation between negative behavior and achievement. To apply this concept into the field of second language learning, the researchers focus on the relationship of negative classroom behavior with the students' speaking performance. The standard model of this relation reads students with less negative behavior would perform better than those who display more cases of negative behavior. This study attempts to confirm this model.

\section{Literature Review on Students' Behavior}

\subsection{The Need to Mitigate Negative Behaviors and Promote Positive Ones}

Based a number of governmental reports, behavioral problems of the students need to be accommodated accordingly. Those reports amplify that schools and government need to react actively to reinforce order at schools. According to Steer (2005), all parties including staff and teachers at school should manage to control classroom behavior related with the following issues:

1) Learning quality, teaching quality and behavior cannot be separated and they are linked with each other.

2) Schools should take action to create appropriate behavior of pupils and disrupting behavior shall be minimized

3) Schools should improve their standard of students' behavior

4) Parents should also help to maintain students' supportive behavior

Steer and his group belief that students' behavior is a serious national problem and needs to be studied and solved seriously by the government and schools. Comparison of students' behavior in different countries especially the developed ones need to be compiled in a standardized benchmark.

Statement with the same tone is also made by the Education Committee of the House of Common (2011). The following is the excerpt which emphasizes the importance of creating order at school.

Good order is essential in a school if children are to be able to fulfill their learning potential. Poor and disruptive behavior in the classroom reduces children's ability to concentrate and absorb information; and it unsettles children and causes immense stress for teacher

Steer and his group are not alone in trying to set an accommodative behavioral standard across classrooms in their region. Manitoba Education (2011) have arranged comprehensive aspects to be controlled in order to achieve the desired classroom behaviors in Manitoba Classrooms. Those aspects include: 
1) Positive Relationship among parties

2) Classroom Organization

3) Differentiated Instruction

4) Classroom Behavioral Expectation

5) Social Skills Instructions

6) Positive Reinforcement

7) Fair and Predictable Consequences

8) Gathering Data to Understand Student behavior

9) Planning for Behavioral Changes

The government of Manitoba argues that with general intense intervention from the government and schools, most students with general needs and a number of students with special behavioral needs can benefit from the standardized behavioral protocol.

Irish International Teachers' Organization (2004) explain that negative behaviors of the students often manifest in the following types of behavior:
1) Aggressive Behavior
2) Disruptive Behavior
3) Destructive Behavior
4) Withdrawn Behavior
5) Stereotypical Behavior
6) Self-injurious Behavior

If most of the papers above mentioning the standardization of behaviors related to the effects to others, there is a very personal approach designed by School of Medicine New York University to assess individual school problem behaviors. There are some issues raised by the findings (Bobrow, 2002):

1) Behaviors can and shall be rewarded by something tangible.

2) Behaviors can be rewarded by attentive support

3) Behaviors can reflect avoidance of unpleasant situation

4) Behaviors can change mood or mental energy.

If those four motives fail to produce good behavior, school should take the following steps:

1) Interview with teacher and/or other referring professionals

2) Review of student's record to see some patterns

3) Interview the parents to see the similar experiences at home

4) Interview the students in the form of supportive discussion. (Not applicable for some minority students)

5) Direct observation

From the findings of the current studies and recommendation from different governments from different parts of the world, almost all authoritative parties believe that behavior at school needs to be controlled, maintained and standardized.

\subsection{Predicting Academic Achievement from Behavior}

A number of studies have shown positive correlation between positive behavior and academic achievement. Jeynes (2003:179) argues that not only the students' behavior at school have impact on their academic outcome, but also their behaviors outside the school. Scott et al. (2001:312) in Sailor et al. (2008:525) have identified three relational effects between behavior and academic achievement. Firstly, there is a strong correlation between the act of avoiding mistakes and the success in academic results. Secondly, students who rigorously look for attention tend to have academic problem. Thirdly, intervention to reduce misbehavior has led to positive academic results.

Weiner and Craighead (2010:322) through some longitudinal studies have shown that behavior is a strong predictor of academic success. The example taken from an elementary school indicates that the students' memory is related with their behavioral competence. 
Some observable behaviors such as students obedience upon rules, students learning expectation, students' interest and involvement in the classroom have been suspected as important factors to master subject matter at school (Birch \& Ladd, 1997; Feshbach \& Feshbach, 1987; Wentzel, 1993, in Flynt, 2008:8). On the other hand, negative behaviors such as inattention, distractibility, and withdrawn apparently contribute to negative academic outcomes (Akey, 2006; Kane, 2004, in Flynt, 2008:8).

Wentzel (1993:85) has studied the relationship between classroom behaviors and the academic achievement among middle school students. The behaviors observed include pro-social, antisocial, and academically oriented behavior. The study concludes with the significant relation between those predictors and academic achievement. Hulya (2004) adds similar findings showing that positive behaviors generally relate with higher reading and math achievement scores. Stronger statement made by Horn and Packard (1985:77) reveal that distractibility and poor impulse control at earlier age of the students can become a predictor of academic success in the later future.

\section{Research Methodology}

This study attempts to confirm the model confirmed by the previous studies on the relation between behavior and academic achievement. The model reads positive behaviors lead to good academic results and negative behaviors lead to unsatisfactorily academic results. The researchers' background is applied linguistics and that encourages them to investigate the correlation between negative behavior and language performance. The subjects of the study are 40 junior high school students from the same class at a school in Central Java, Indonesia. Junior high school students are chosen as participants because at this period of time, there is a transitional process from childhood to adolescence where behavioral changes can be expected.

The list of negative behaviors in this study is adapted from Woodcock Johnson III test (Schrank \& Woodcock, 2002). There are eight negative behaviors listed in this study: Inattentive, Overactive, Impulsive, Uncooperative, Anxious, Withdrawn, Aggressive and Nonaggressive. The students were asked to reevaluate themselves whether they have one or more than one symptoms. Each negative behavior is scored 1 (one). It means that the lowest score for each students is 0 (if the don't have any negative behavior at all) and the highest score is 8 (if the students have all the negative behavior listed). The answers from the students are elicited by the researchers using local language in order to avoid confusion among subjects.

Language performance is represented by speaking skill evaluation. The speaking test uses the criteria adapted from Haris (1969). The students are given a certain task they are scored by three raters. The three raters show fair inter-rater agreement test calculated using Fleiss Kappa method.

It needs to be emphasized that this is a self-evaluation study. The results of this study really depend on how the students perceive and evaluate themselves. The method is significantly different from direct observation using checklist provided by WJIII. Direct observation has been used by the researcher in the previous study and the results show that there is no significant correlation between negative behavior and speaking performance in second language (Sagita, 2013). This time, the researchers try to see the results from different angle. There is a possibility that students' self-evaluation might be different from the direct observation. It leads to the possibility that students' self-evaluation may correlate with speaking performance.

\section{Results and Discussion}

In the previous study conducted by the researchers, negative behaviors were directly observed and tallied. The value of the tally was then processed using linear regression against their corresponding speaking scores. The statistical analysis shows Pearson Correlation score of -0.183 . It means that observed negative behaviors have negative correlation with speaking scores but the correlation is quite weak.

In this study, the same set of data of speaking scores is used to represent the dependent variable. However, the direct observation of negative behaviors is replaced by self-evaluated negative behaviors elicited from closed interview with the students.

The results of the self-evaluated negative behaviors and the speaking scores from the 40 students can be recapitulated in the following scatter plot: 


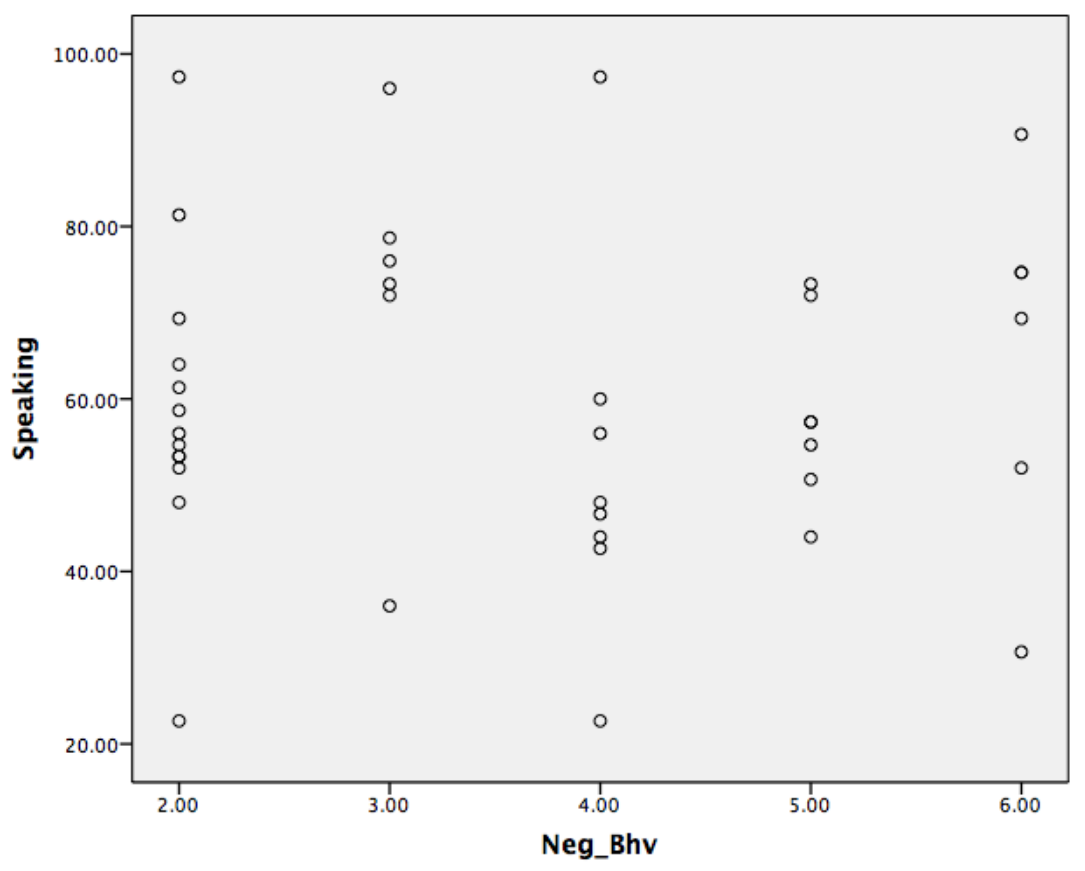

Figure 1. Scatter Plot of Self-Evaluated Negative Behavior and Speaking Scores.

From the scatter plot, we can see no trend governing the correlation between self-evaluated negative behaviors and speaking scores. Further calculation using SPSS software shows that the Pearson's $r$ analysis produces 0.004 showing that the correlation is very weak.

\begin{tabular}{|c|c|c|c|c|}
\hline \multicolumn{5}{|c|}{ Model Summary } \\
\hline $\begin{array}{l}\text { Mod } \\
\text { el }\end{array}$ & $\mathrm{R}$ & $\begin{array}{c}\mathrm{R} \\
\text { Square }\end{array}$ & $\begin{array}{c}\text { Adjusted R } \\
\text { Square }\end{array}$ & $\begin{array}{l}\text { Std. Error } \\
\text { of the } \\
\text { Estimate }\end{array}$ \\
\hline 1 & $.004^{a}$ & .000 & -.026 & 18.67026 \\
\hline
\end{tabular}

a. Predictors: (Constant), Neg_Bhv

Figure 2. Data Output of SPSS calculating the Correlation between Self Evaluated Negative Behavior and Speaking Scores.

\section{Conclusion}

At the beginning of this study, the researchers have reviewed the literature showing that there are ample claims stating that there is a strong correlation between students' behaviors at schools and academic achievement. The results of this study have not supported the claims made by the literature. The regression analysis in this study shows that there is a little or no correlation between self-evaluated negative behaviors and speaking performance. In regression analysis, it is expected to get $r$ value closer to 1 or -1 . Pearson's value closer to 0 means that the correlation is weak or even non-existence. The Pearson's $\mathrm{r}$ of 0.004 does not bear any meaningful correlation between self-evaluated negative behavior and speaking scores. Hence, the absence or presence of negative behaviors cannot be used as predictors of academic achievement according to the results of this study. The results of this study supported the previous study conducted by the co-researcher which devised direct observation of negative behaviors producing similar results.

Cautions shall be made related with the limitation of this research:

1) The number of the subjects and the convenient sampling system are not ideal to generalize the results of the study.

2) The presence and absence of negative behavior cannot directly relate to the presence and absence of positive behavior.

3) There is no control variable which can be manipulated due to the limitation of the resource. 
4) Future studies should involve multiple variables and approaches in order to portray different angles of the correlation.

All in all, there is always a strong advice from the government and experts to prevent negative behaviors in order to improve academic success. This claim needs to be substantiated with sound empirical studies. This study tries to provide such empirical data and has failed to indicate any correlation between two variables. Regardless the results, the researchers still support the government's, schools' and teachers' efforts to mitigate students' negative behavior.

\section{Reference}

Bobrow, A. (2002). Problem Behaviors In The Classroom: What they mean and how to help. Chid Study Center Letter, 7(2), 1-4. Retrieved from http://www.aboutourkids.org/files/articles/nov_dec_2.pdf

Flynt, C. J. (2008). Predicting Academic Achievement from Classroom Behaviors. A dissertation. Faculty of the Virginia Polytechnic Institute and State University.

Horn, W. F., \& Packard, T. (1985). Early Identification of Learning Problems. Journal of Educational Psychology, 77, 597-607. http://dx.doi.org/10.1037/0022-0663.77.5.597

House of Commons. (2011). Behaviour and Discipline in Schools. http://www.publications.parliament.uk/pa/cm201011/cmselect/cmeduc/516/516i.pdf

Hulya, E. (2004). Relationship between Students Characteristics and Academic Achievement in Distance Education and Application on Students of an Anadolu University. The Turkish Online Journal of Distance Education, 5(2), 81-100.

Irish National Teachers' Organization. (2004). Managing Challenging Behaviour: Guidelines for Teachers. Available from http://www.into.ie/ROI/Publications/ManagingChallengingBehaviour.pdf

Jeynes, W. (2003). Religion, Education, and Academic Success Research on religion and education.United States of America: IAP.

Manitoba Education. (2011). Towards Inclusion: Supporting positive behaviour in manitoba classrooms. Available from http://www.edu.gov.mb.ca/k12/specedu/behaviour/behaviour_document.pdf

Sailor, W., Dunlap, G., Sugai, G., \& Horner, R. (2008). Handbook of Positive Behavior Support Issues in Clinical Child Psychology. United States of America: Springer.

Schrank, F. A, \& Woodcock, R. W. (2002). Report Writer for the WJ III Compuscore and Profiles Program [Computer Software]. Itasca, IL: Rivershide Publishing.

Steer, A. (2005). Learning behaviour: the report of the Practitioners' Group on School Behaviour and Discipline. Available from http://www.educationengland.org.uk/documents/pdfs/2005-steer-report-learning-behaviour.pdf

Weiner, I. B., \& Craighead, W. E. (2010). The Corsini Encyclopedia of Psychology, New Jersey: John Wiley \& Sons, 1. http://dx.doi.org/10.1002/9780470479216

\section{(cc) EY}

This work is licensed under a Creative Commons Attribution 3.0 License. 